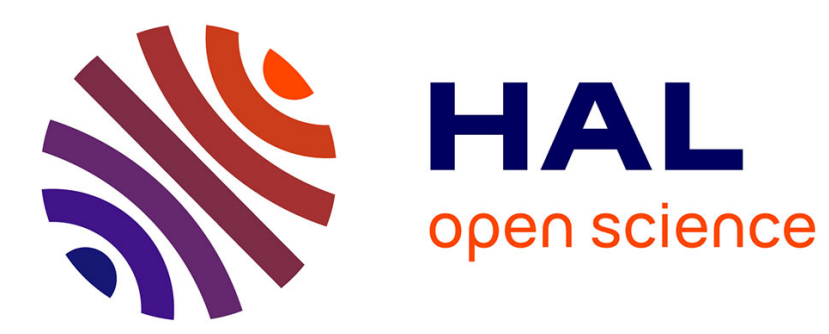

\title{
Raman Identification of Ancient Stained Glasses and their degree of deterioration
}

Philippe Colomban, Marie-Pierre Etcheverry, Magali Asquier, Mathieu

Bounichou, Aurélie Tournié

\section{- To cite this version:}

Philippe Colomban, Marie-Pierre Etcheverry, Magali Asquier, Mathieu Bounichou, Aurélie Tournié. Raman Identification of Ancient Stained Glasses and their degree of deterioration. Journal of Raman Spectroscopy, 2006, 37, pp.614-626. hal-00120398

\section{HAL Id: hal-00120398 https://hal.science/hal-00120398}

Submitted on 14 Dec 2006

HAL is a multi-disciplinary open access archive for the deposit and dissemination of scientific research documents, whether they are published or not. The documents may come from teaching and research institutions in France or abroad, or from public or private research centers.
L'archive ouverte pluridisciplinaire HAL, est destinée au dépôt et à la diffusion de documents scientifiques de niveau recherche, publiés ou non, émanant des établissements d'enseignement et de recherche français ou étrangers, des laboratoires publics ou privés. 
The aim of this investigation was to establish a Raman procedure for on-site identification of stained glass windows and their deterioration level. A large selection of ancient glasses and modern replica have been analysed with IR and Raman spectroscopy, optical microscopy and EDS. Criteria for in situ Raman measurements of the weathering degree of ancient stained glasses are proposed.

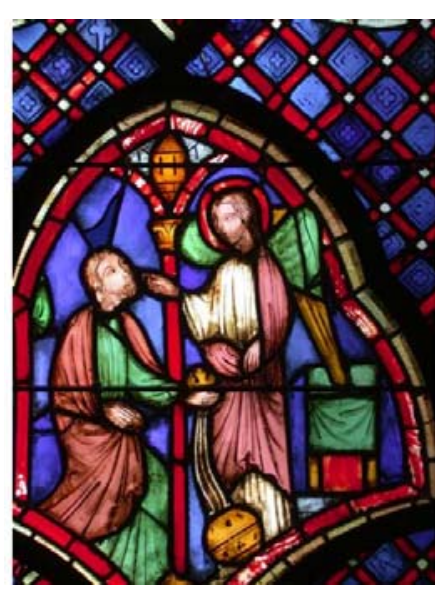

Raman Identification of Ancient Stained Glasses and their degree of deterioration

Philippe Colomban, Marie-Pierre Etcheverry, Magali Asquier,

Mathieu Bounichou, Aurélie Tournié 


\title{
Raman Identification of Ancient Stained Glasses and their degree of deterioration
}

\author{
Philippe Colomban ${ }^{1 *}$, Marie-Pierre Etcheverry ${ }^{2}$, Magali Asquier ${ }^{1}$, Mathieu Bounichou ${ }^{1}$, \\ Aurélie Tournié ${ }^{1}$ \\ ${ }^{1}$ Laboratoire de Dynamique, Interaction et Réactivité (LADIR), UMR 7075 Centre National \\ de la Recherche Scientifique \& Université Pierre et Marie Curie, 2 rue Henri Dunant, 94320 \\ Thiais, France \\ ${ }^{1}$ Laboratoire de Recherche des Monuments Historiques (LRMH), 29 rue de Paris, 77420 \\ Champs-sur-Marne, France
}

\begin{abstract}
The aim of this investigation was to establish a Raman procedure for on-site identification of stained glass windows and their deterioration level. This study of a representative series of stained glass pieces dating from the $13^{\text {th }}-17^{\text {th }}, 19^{\text {th }}$ and $21^{\text {st }}$ centuries made it possible to classify the glasses into four types: Type 1 (rare, Ca-rich Na silicate), Type 2 (rare, Na-rich, Ca silicate), Type 3 (more frequent, K-Ca silicate) and a variant of Type 3, referred to as 3 bis. Ion exchange of the alkali cations has been made in boiling sulphuric acid and related to structural and compositional changes, which have been analysed with IR and Raman spectroscopy, optical microscopy and EDS. Measurements of the film thickness show a great discrepancy between the ion exchange rates of K-Ca (Type 3: $60 \mu \mathrm{m} / \mathrm{h}$ ) and Na-Ca (Type 2: $15 \mu \mathrm{m} / \mathrm{h})$ silicates with that of Type 1 Ca-silicate $(0.05 \mu \mathrm{m} / \mathrm{h})$. IR and Raman spectra provided proof that the nanostructure of the glass has been modified, chiefly by the downwards (Raman) and upwards (IR) shift of the position of the main Si-O stretching peak and a decrease in the intensity of the Boson peak, as well as the Raman $580 \mathrm{~cm}^{-1} \mathrm{Si}-\mathrm{O}$ bending peak. The decrease in intensity of the narrow $\sim 950 \mathrm{~cm}^{-1}$ Raman peak, assigned to (earth)alkali nano crystallites in the glassy network, is correlated to $\mathrm{K} / \mathrm{Na}$ ion loss and glass weathering. Consequently Type 3 bis samples are in fact glasses, from which the surface is depleted of $\mathrm{K} / \mathrm{Na}$ ions. Optical micrographs support the macroscopic compositional and structural heterogeneity of the ancient glasses. This work demonstrates the potential of Raman scattering for in situ measurements of the weathering degree of ancient stained glasses.
\end{abstract}

Keywords: glass, silicate, conservation, Raman spectroscopy, IR, weathering, stained-glass window

*corresponding author

fax : 33149781118

philippe.colomban@glvt-cnrs.fr 


\section{INTRODUCTION}

The weathering of stained glass windows of ancient churches and cathedrals results in colour changes and in some instances even severe physical damage [1-15]. The environment to which the glass is exposed greatly influences the deterioration rate and even museum conservation wood cases promote the deterioration of glass items [16]. Alteration of the glass is attributed to a reaction between the glass surface and aqueous solutions in a two-stage process [6-15]. The first stage is an ion exchange process between protonic species from the surface liquid and an alkali ion, which is removed from the glass and results in the formation of an alkaline wet film on the surface. This film becomes increasingly alkaline and above $\mathrm{pH}$ 9 the second stage occurs, with decomposition of the silica network. As a non-destructive technique, Raman spectroscopy has proved its potential in the analysis of the structure of amorphous silicates [17-22]. However, a lot of information about the production process still remains written in the sample and non-destructive Raman analysis of the micro-structure (by analysing different positions with a microscopic resolution) and nano-structure (through the analysis of the Raman spectra itself) offers a way to retrieve the information, which assists in the identification and sometimes dating of ancient artifacts. On-site analysis is now possible with the use of portable instruments [18]. Many properties of a glass depend on its chemical composition, which is a result of the kind and ratio of the raw materials used in the batch (mixture of raw materials). All applications in the science, art and technology of glass, glazes and enamels consist out of a controlled modification of the 3D Si-O network by replacement of $\mathrm{Si}^{4+}$ covalent bonded atoms by non-covalent bonded atoms, hence decreasing the number of Si-O bridges and the connectivity of the network. Consequently, the melting temperature (and the viscosity at a given temperature) decreases. Other physical/chemical properties related to the density and network connectivity (thermal expansion, ion diffusion, reactivity, etc.) are modified accordingly. Direct relationships between the silica content, or more precisely the ratio between the glass-former (chiefly $\mathrm{Si}$ and $\mathrm{Al}$-oxides) and the flux (Na, K, $\mathrm{Ca}, \mathrm{Pb}$ oxides) content and the properties of glassy silicates have been established for a long time (Seeger's rules and modern developments by Stevels, Huggins, etc [see e.g. references in 12]). Because strong covalent bonded structures have Raman signatures orders of magnitude larger than those of ionic ones, the Raman spectrum of a silicate consists, as a first approximation, solely out of the signature of the Si-O network ( $\mathrm{Si}-\mathrm{O}$ stretching, bending and librational/collective modes) [21]. Because a $\mathrm{SiO}_{4}$ tetrahedron is a solid chemical and vibrational entity (molten silicates retain a strong polymeric character), it is well established 
that the different tetrahedral arrangements: a isolated tetrahedron referred to as $\mathrm{Q}_{0}$, tetrahedra linked by a common oxygen atom $\left(\mathrm{Si}_{2} \mathrm{O}_{7}\right.$ or $\left.\mathrm{Q}_{1}\right)$, tetrahedra linked by sharing 2 oxygen atoms (three $\left(\mathrm{Si}_{3} \mathrm{O}_{9}\right)$ and $\mathrm{n}$ tetrahedral-cycles: $\mathrm{Q}_{2}$ ), by sharing 3 oxygen atoms (e.g. in some chains, ribbons and layers) and $\mathrm{Q}_{4}$ (as in pure $\mathrm{SiO}_{2}$ ) have characteristic Raman signatures [18-22].

Our first purpose is the classification of representative samples of ancient (Middle Age) and recent $\left(19^{\text {th }}\right.$ century) stained glasses from various cathedrals and churches of France (Amiens, Le Mans, Beauvais, Strasbourg, Rouen and Aube country, ...), and glass replicas specially prepared for conservation studies (Sainte-Chapelle, Paris, Saint-Urbain, Troy and Köln Dom, $\left.21^{\text {st }} \mathrm{c},[23,24]\right)$. We will try to establish the Raman signatures of the different types of compositions used in the preparation of stained glasses: sodium-rich (probably prepared from sodium carbonate or other salts) [12] or potassium-rich (most likely prepared from plant ash) ancient glasses [12], in order to define a database for on site identification. One sample of each type was selected to use for ionic exchange in boiling sulfuric acid. This technique has previously been used to study the corrosion mechanism of sophisticated glass and glassceramics used in the aeronautic industry [25], in particular to highlight the diffusion path distribution [26,27]. Our objective is the quantification the degree of weathering and a better understanding of the glass window deterioration mechanisms.

\section{EXPERIMENTAL}

\section{Samples}

The objects analyzed are listed in Table 1. A selection of them is shown in Plate 1. Pieces of stained glass windows were analyzed as received, without any cleaning or preparation.

\section{Ion exchange}

Ion exchange was performed in a Pyrex round bottomed flask using concentrated sulfuric acid, with the volume of acid $\sim 100$ times the sample volume [28]. We used a sand filled box with a resistor, able to reach $500^{\circ} \mathrm{C}$, inside. A glass double tube with water-cooling was used to condense the sulfuric acid vapor. Placing the flask in hot sand rapidly heated the samples, which were then exposed to the treatment process for time durations ranging between 5 minutes and 20 hours. Samples were washed in water 3 times and placed in an ultrasonic device for a few minutes to eliminate any soluble sulfates. 


\section{Techniques}

A multichannel notch-filtered INFINITY spectrograph (Jobin-Yvon-Horiba SAS, Longjumeau, France) equipped with a Peltier cooled CCD matrix and two "XY" spectrographs (Dilor, Lille, France) equipped with a double monochromator filter and a backilluminated, liquid nitrogen-cooled, 2000 x 256 pixels CCD detector (Spex, Jobin-YvonHoriba Company) were used to record Raman spectra between 10 (XY instrument)/150 (INFINITY instrument) and $2000 \mathrm{~cm}^{-1}$, using 457, 488, 514.5, 532, and $647.1 \mathrm{~nm}$ exciting lines $\left(\mathrm{Ar}^{+}-\mathrm{Kr}^{+}, \mathrm{YAG}\right.$, and $\mathrm{He}-\mathrm{Ne}$ lasers $)$. The power of illumination ranged between $0.5 \mathrm{~mW}$ (INFINITY instrument, red samples) and $10 \mathrm{~mW}$ (XY instrument, nearly colourless samples) as a function of the sample colour, instrument, and wavelength. Backscattering illumination and collection of the scattered light were made using a macro-setting (volume analysed $\sim 500$ $\mu \mathrm{m})^{3}$ and through an Olympus confocal microscope (long focus Olympus x50, x80 or x100 objective, total magnification $\mathrm{x} 500, \mathrm{x} 800$ or $\mathrm{x} 1000)$. A systematic examination was made of the glass surface with the $x 50$ objective. Ion-exchanged samples were analysed using the macro setting (XY instrument) and the x100 objective (Infinity instrument); we decreased the size of the confocal hole, in order to reduce the size of the in-depth analysed volume to a few microns. The spectrometer microscope was used to record optical micrographs.

IR spectra were obtained of samples pressed into CsI pellets, using a 980 Perkin Elmer double-beam spectrometer. Pieces were broken off, in order to separate visually, grains made of pristine glass from those made of corroded film and then each part was separately powdered in an agate mortar.

\section{Compositions}

A scanning electron microscope (LEO 1530 instrument) was used for the semi-quantitative determination of the compositions of ion-exchanged samples. The samples were cut in 3-5 mm plates and covered with a thin Au-Pd film. The EDX analysis (EGG instrument, Bruker software) was then performed in the range between 1 and $15 \mathrm{keV}$. The analysis could be performed on an area several $\mu \mathrm{m}$ in diameter.

A series of samples from the bulk of the material were embedded in a polyester SODEMI H59 resin, polished and observed using a Jeol JSM 5600 Low -Vacuum SEM; further analyses of the microstructure were made using a Jeol JSM 840 in order to determine mean glass composition (Link ISIS system, ZAF quantitative correction method). Compositions of glass 
replicas made in the $21^{\text {st }}$ century are taken from ref [23]. These K-lime silica glasses, replicating $13^{\text {th }}$ and $14^{\text {th }}$ centuries glass compositions of three ancient monuments, were exposed in situ during one year in-field experimentation by VIDRIO, the European programme for stained-glass window conservation [24].

\section{Peak fitting and data processing}

In undertaking a curve fit of the Raman spectra, a linear baseline was first subtracted using LabSpec ${ }^{\circledR}$ software as previously discussed [29]. We selected a 4-segment baseline: $\sim 150-700,700-890,890-1300$ and $1300-1700 \mathrm{~cm}^{-1}$ for a reproducible separation of the different components of the Raman signatures. The same spectral windows were used for the extraction of the components using the Origin ${ }^{\circledR}$ software peak-fitting module (Microcal Software, Inc.). The integral area, the bandwidth and the centre of gravity were calculated for each component using the $\mathrm{Q}_{\mathrm{n}}$ model [21,22]. This model allows for a comparison of the glassy silicate nanostructure over a large composition range. A Gaussian shape was chosen for all Raman lines assigned to glassy silicates because of the amorphous state of the examined materials. A Lorentzian shape was used for narrow components.

Silicate structures consist of more or less connected (polymerized) $\mathrm{SiO}_{4}$ tetrahedra. Because the $\mathrm{SiO}_{4}$ tetrahedron is a very well defined vibrational and structural entity, its different configurations have specific vibrational fingerprints. The different spectral components provide information on the connectivity of the $\mathrm{SiO}_{4}$ polymeric units and thus on the glass composition, nanostructure and processing temperature. A clear differentiation is possible through the relative intensities of the components of the Si-O stretching and bending modes at ca. 1000 and $500 \mathrm{~cm}^{-1}$ respectively and $I_{P}$, the polymerisation index, defined as $I_{P}=$ $\mathrm{A}_{500} / \mathrm{A}_{1000}$ with $\mathrm{A}$ being the area under the Raman band. From the literature ([17-23] and refs therein) the different spectral components of the stretching envelope were assigned to specific silica vibrations. The following assumptions were made: i) for the Si-O stretching range extending from 700 to $1300 \mathrm{~cm}^{-1}$ (see previous work), we postulated 5 components namely $\mathrm{Q}_{0}, \mathrm{Q}_{1}, \mathrm{Q}_{2}, \mathrm{Q}_{3}$ and $\mathrm{Q}_{4}$ according to the number of oxygen atoms bonded per tetrahedron, ii) we also postulated 5 bands with similar bandwidths for Si-O bending components iii) one or two narrow bands were added, if necessary, to take crystalline phases into account. 


\section{RESULTS}

\section{Classification}

Fig. 1 shows representative Raman spectra recorded on the samples listed in Table 1 (photographs in Plate 1). In this preliminary work, we identified 3 types of Raman signatures, referred to as Type 1, 2 and 3 (see Fig. 2 for selected spectra with decomposition of the $Q_{n}$ components and Table 2 for the corresponding $Q_{n}$ and $I_{p}$ values). The signatures of red flashed glass and of silver-yellow painted glass will not be considered here, because of the unique character of the Raman signature of material with a metal nanoprecipitate distribution [30].

Type 3 glass corresponds to group $6\left(" \mathrm{~K}_{2} \mathrm{O}+\mathrm{CaO}\right.$ " glass) according to our previous classification of glassy silicates [17,21,29] whilst Type 1 and Type 2 glasses belong to group 3 (" $\mathrm{Na}_{2} \mathrm{O}+\mathrm{K}_{2} \mathrm{O}+\mathrm{CaO}$ " glass), a group which encompass most of the ancient glasses, e.g. the Phoenician-Roman glasses [31]. Characteristic component wavenumbers and peak areas are given in Table 2: after subtraction of a linear segment baseline (see refs [22] \& [29] for a discussion of the procedure). The Type 3 signature consists in a strong Si-O bending peak at 590-620 $\mathrm{cm}^{-1}$ and a strong broad Si-O stretching peak at $\sim 1080-1090 \mathrm{~cm}^{-1}$, with a narrow peak at $\sim 950 \mathrm{~cm}^{-1}$.

The Type 2 signature is rare (only one occurrence, the AM19jaune glass); the intensity of the $950 \mathrm{~cm}^{-1}$ peak is greatly diminished and the main Si-O stretching mode peaks at $\sim 1100 \mathrm{~cm}^{-1}$. Additionally, a rather strong peak is observed at $\sim 460 \mathrm{~cm}^{-1}$. The Type 1 signature is recognizable from the $950-995 \mathrm{~cm}^{-1}$ doublet and the rather large area of the $450 \mathrm{~cm}^{-1}$ band. An additional Type 4 signature is observed in the red copper doped layer of flashed glass with a characteristic strong $\sim 500 \mathrm{~cm}^{-1}$ component and $625 \mathrm{~cm}^{-1}$ shoulder [30] and will not be discussed in this paper.

A group of glass that we refer to as 3 bis has a signature, which are similar to the Type 3 signature but with the following obvious differences: the intensity of the $450 \mathrm{~cm}^{-1}$ broad peak is larger and many components are observed. Note that all these glasses exhibit a lot of corrosion dots (Plate 1).

Comparison with the EDS analysis shows that Type 1 glass is a Ca-rich, $\mathrm{Na}$ containing silicate, Type 2 glass is Na-rich, Ca-based silicate and Type 3 glass a K-Ca silicate (Fig. 3). Table 3 compares the mean compositions of a selection of glass of each group (ancient, modern and glass replicas). Obviously, the large structural differences evidenced from the 
Raman spectra are less clear from the simple comparison of the oxide content. The $\mathrm{CaO} / \mathrm{Na}_{2} \mathrm{O}$ and $\mathrm{CaO} / \mathrm{K}_{2} \mathrm{O}$ content ratio must be considered.

\section{Ion exchange and reactivity of the different glasses}

Fig. 4 compares the sample sections obtained by breaking the representative glass pieces after $20 \mathrm{~h}$ thermal treatment in boiling concentrated sulfuric acid. The pristine state and initial color still remains in the core of the bulk of the sample. A more or less thick white or pale colored film is formed all over the surface. The mechanical strength of the film is still high, which is an indication that the glass network connectivity has been preserved. However the loss of transparency indicates that micro-cracks, pores and/or second phases have formed. The thickness of the film has been measured and plotted as a function of time and square root of time in Fig 5. Optical observations on representative sections and surfaces are given in Fig. 6 and the compositional change is illustrated with the EDS spectra in Fig. 3.

The motivation in using sulfuric acid attack is to accelerate the exchange of mobile cations with $\mathrm{H}_{3} \mathrm{O}^{+}$ions, which was confirmed by the presence of the characteristic bending mode at $1750 \mathrm{~cm}^{-1}$ in the IR spectra of the glass [28-32] (see Fig. 7). More complex protonic entities are however possible $[28,32,33]$. It is thus easy to analyze the glass modification with a variety of techniques, including vibrational spectroscopy, a very powerful technique for the study of amorphous silicates.

Type 1 glass is almost insensitive to the action of sulfuric acid. The thickness of the layer modified after $20 \mathrm{~h}$ in sulfuric acid comprises only a few microns $(\sim 0.05 \mu \mathrm{m} / \mathrm{h})$. On the other hand the film layer reaches $\sim 350 \mu \mathrm{m}(\sim 15 \mu \mathrm{m} / \mathrm{h})$ and $\sim 600 \mu \mathrm{m}(\sim 30 \mu \mathrm{m} / \mathrm{h})$ for Type 2 and Type 3 glasses after the same duration of chemical attack (Fig. 5). Plots as a function of the square root of time show a two-step process, first a very slow one and then a fast one with the same activation energy for Type 2 and 3 glasses (straight lines are parallel). EDS analyses show strong $\mathrm{K}, \mathrm{Na}$ and moderate $\mathrm{Ca}-\mathrm{Al}$ loss.

The examination of the microstructure (Fig. 6) showed different phenomena. We will discuss only the results obtained on Type 3 samples after 5 minutes and $20 \mathrm{~h}$ in sulfuric acid, which is representative of the main features.

After 5 minutes in boiling sulfuric acid we observe a modification of the surface: a lot of cracks are formed in the first $10 \mu \mathrm{m}$ of the outer surface and then a regular network of microcracks perpendicular to the surface extend to hundreds of microns deep. This kind of crack formation is consistent with glass shrinkage, as observed for many (earth)alkali silicates 
[25,26], due to the loss of $\mathrm{K}$ ions (Fig. 3). The rather regular distance between the cracks perpendicular to the surface arises from a combination of the shrinkage value due to ion exchange and the mechanical strength of the glass. Note that the distance between cracks is about 10 times smaller in the outer surface. This indicates that the composition of the external surface is different from the bulk and/or that the deterioration mechanism was different, according to the two-step behaviour observed on the thickness plotted as a function of the square root of time.

After $20 \mathrm{~h}$ in sulfuric acid, six different layers are observed (Fig. 6c), from the top surface to the pristine glass core:

- a surface layer, in which $\mathrm{K}^{+}$(and/or $\mathrm{Na}^{+}$) ions has been exchanged by protonic species; this layer is not optically clear anymore. Note that the interface between the opaque surface layer and the substrate is not flat, indicating a large variation in glass reactivity.

- an optically clear layer, with cracks perpendicular to the surface (as observed after 5 min treatment (Fig 6b), in which fractal animal figures are visible.

- a dark nearly flat interphase is observed, superimposed on a layer with some corrosion pathways and cracks.

- Finally, at the interface with the pristine glass, complex round figures indicate localized modifications, which could be linked to heterogeneity in the composition of the pristine glass.

Examination of the glass surface from the top (Fig. 6d) shows a rather regular crack network made of circle cracks linked by rather linear cracks. Such regular circle distribution can be correlated to an ordered heterogeneity.

IR spectra have been obtained of Type 2 and Type 3 powdered cores and films (Fig. 7). Nanostructural changes are evident with the shift of the peak maxima of certain peaks (for example the Si-O-Si mode shifts from 770/775 to 795/800 $\mathrm{cm}^{-1}$ for Type 2 and Type 3 glasses) and the disappearance of many shoulders (e.g. the $950 \mathrm{~cm}^{-1}$ on the main Si-O asymmetric stretching mode). Additionally a weak peak at $\sim 1740 \mathrm{~cm}^{-1}$ is observed in ionexchanged materials, owing to the substitution of alkali ions by oxonium $[26,28,32]$ and the compositional changes illustrated in Fig. 3: see the strong decreases of the $\mathrm{Na}$ and $\mathrm{K}$ (and $\mathrm{Al}$ ) EDS signature in films.

In this preliminary investigation, we limited our Raman analyses to the upper surface. The analysis of the interphase between the homogeneous film and the sound pristine glass will be 
presented in a further paper. Representative Raman spectra are given in Fig. 8 for samples after different periods of time attack in sulfuric acid. We observe :

- a shift of the main Si-O stretching peak from 1090 (Type 1 and 2 glass) or $1075 \mathrm{~cm}^{-1}$ (Type 3 glass) to 1080 (Type 1), 1070 (Type 2) and 1060 (Type 3) $\mathrm{cm}^{-1}$.

- a decrease of the intensity of the broad Si-O bending peak $\left(\sim 570 \mathrm{~cm}^{-1}\right)$ and of the $\sim 950$ $\mathrm{cm}^{-1}$ narrow component.

- a decrease of the Boson peak.

All these changes indicate a modification of the silicate network according to shrinkage and the loss of $\mathrm{Na}^{+}, \mathrm{K}^{+}$and to a lesser extent of $\mathrm{Al}^{3+}$ and $\mathrm{Ca}^{2+}$ ions.

\section{DISCUSSION}

Important results were obtained from this preliminary study Firstly, ion-exchange substitution of $\mathrm{K}^{+}$and $\mathrm{Na}^{+}$ions induced clear modifications of the Raman signature and strong discrepancies are observed between the different types of glass. Obviously the 3 bis Type glass corresponds to weathered silicates in the analyzed surface volume, about 10 to $50 \mu \mathrm{m}$ depth for our conditions . Visual observation of these samples (Plate 1) shows many white pits at the glass surface made of complex carbonates/sulfates as secondary alteration products. Raman data were always collected in areas outside the pits, in the apparently "safe" glass. Then our objective to establish Raman scattering as an on-site measurement technique of the corrosion degree appears to be a reasonable target.

Cut glass cross-sections exposed different layers with both homogeneous and heterogeneous characters. In the future we will try to examine the Raman signature of the different zones, in order to confirm if this behaviour is related to compositional or structural heterogeneity of the original glass. Note that such complex figures of corrosion have been reported for a long time without a clear explanation [6,9]. It is important to notice that the microcrack network observed at the sample surface (Fig. 6) is less "fractal" that those observed for lithium aluminosilicate glasses in which conducting pathways are tubular [26,27]. In particular we observe from place to place circular cracks which support compositional and structural heterogeneity (for instance, $\mathrm{Na} / \mathrm{K} / \mathrm{Ca}$-rich and $\mathrm{Na} / \mathrm{K} / \mathrm{Ca}$ - poor, silica-rich regions, as sketched in Fig. 9). Local composition heterogeneity have been already postulated in the Modified Random Network [34].

The polymerization index of the pristine glasses are rather similar ( 0.9, Table 2$)$. This is not surprising because whatever the composition of raw materials, glass manufacturers 
endeavoured to obtain a material that they could prepare in the same range of temperatures (our previous work have unambigously established the strong correlation between the polymerization index and the processing temperature of glassy silicates $[21,22])$. Note the scattering of the value is close to 0.2 for both Type 1 and Type 2 groups. The polymerization index measured for $\mathrm{Na} / \mathrm{K}$-depleted glasses is higher $(\sim 1.1)$, according to the loss of alkali ions and of some less connected $\left(\mathrm{SiO}_{4}\right)_{\mathrm{n}}$ entities, equivalent to an increase of the silica content in depleted film. These conclusions are correlated with the EDS analysis and with the increase of the $\sim 450 \mathrm{~cm}^{-1} \mathrm{Si}-\mathrm{O}$ bending peak. The disappearance of the narrow peak at $\sim 950 \mathrm{~cm}^{-1}$, assigned to potassium/calcium silicate nanocrystals (the correlation between potassium content and the intensity of this peak was previously noted [35]) confirms that less connected entities are unstable in acidic environments and that they are not only related to the potassium content but also to the calcium content. Note that the strong and narrow $950 \mathrm{~cm}^{-1}$ peak position is very similar to that of wollastonite, a calcium nesosilicate that precipitates very easily in Ca-saturated glasses and glazes [17]. The relatively small FWHM of this peak was not expected for an usual $\mathrm{Q}_{1}$ or $\mathrm{Q}_{2}$ component of a glassy silicate and fits better as a signature of some nano-crystals dispersed in the glass. However, the $950 \mathrm{~cm}^{-1}$ peak is stronger than the $\sim 1060 \mathrm{~cm}^{-1}$ one for Ca-rich glass (for instance Köln $\mathrm{C} 2$ glass: $\mathrm{SiO}_{2} \sim 46 \mathrm{wt} \%, \mathrm{~K}_{2} \mathrm{O} \sim 11 \%$ and $\mathrm{CaO} \sim 30 \%$ ). Obviously the plot of the $950 \mathrm{~cm}^{-1}$ intensity versus the wavenumber of the $v$ Si-O stretching 1060 to $1090 \mathrm{~cm}^{-1}$ component as a function of the $\mathrm{K}$ and Ca content, would be very useful to promote the understanding of the relationship between the Raman signature and glass composition. Fig. 10 shows the plot of the area of the $\sim 590 \mathrm{~cm}^{-1}$ peak (normalized with respect to the other components of the $\delta \mathrm{Si}-\mathrm{O}$ envelope) as a function of the $950 \mathrm{~cm}^{-1}$ one (normaliszed with respect to the other components of the $v$ Si-O envelope). Highest values, close to 0.9 are measured for Type 3 glasses although much lower values are obtained for Type 3 bis weathered glasses. Simultaneously the wavenumber of the $v$ Si-O maxima shifts downwards. Substitution of alkali ions by oxonium and associated loss of less polymerized $\left(\mathrm{SiO}_{4}\right)_{\mathrm{n}}$ entities (also seen by the accompanied loss of $\mathrm{Al}^{3+}$ ion), does not only modify the geometry of the Si-O-Si- network but involves changes in oxygen polarization and hence in Raman band intensity, a poorly documented subject.

\section{CONCLUSION}


The study of a representative series of stained glass dating from the $13^{\text {th }}-17^{\text {th }}, 19^{\text {th }}$ (modern) and $21^{\text {st }}$ centuries (glass replicas) enabled us to preliminary classify the glasses into four types, Type 1 (rare Ca-rich silicate), Type 2 (extremely rare, Na-rich, Ca-silicate), Type 3 (main group, K-Ca silicate) and a variant Type 3 referred to as 3 bis. Ion exchange of the alkali cation took place in boiling sulfuric acid to mimic the first step of the glass deterioration and subsequent structural and compositional changes have been analyzed with IR and Raman spectroscopy, optical microscopy and EDS. Measurements of film thickness show a great discrepancy between the ion exchange rates of K-Ca (Type $3: 60 \mu \mathrm{m} / \mathrm{h}$ ) and Na-K (Type 2: $15 \mu \mathrm{m} / \mathrm{h})$ silicates with that of Type 1 silicate $(0.05 \mu \mathrm{m} / \mathrm{h})$, a very stable glass. IR and Raman spectra provided evidence of nanostructural modifications, chiefly the downwards (Raman) and upwards (IR) shift of the main Si-O stretching peak and the decrease in intensity of the Boson peak, as well as the Raman $580 \mathrm{~cm}^{-1} \mathrm{Si}-\mathrm{O}$ bending peak. The intensity of the narrow $\sim 950 \mathrm{~cm}^{-1}$ Raman peak, assigned to (earth)alkali nano crystallites in the glassy network, is correlated to the $\mathrm{K} / \mathrm{Na}$ loss and glass deterioration. Consequently Type 3bis samples are in fact glass of which the surface is depleted of $\mathrm{K} / \mathrm{Na}$ ions and both the ratio of the $\sim 460 / 590$ and $950 / 1090 \mathrm{~cm}^{-1}$ peak area appears to be a good parameter to quantify the deterioration degree of stained glasses (Fig. 10). Optical micrographs show the macroscopic heterogeneity of the ancient glass nanostructure and composition, which supports similar heterogeneity at shorter scale (see the sketch in Fig. 9), with preferential "regions" for ion diffusion. In our future work we hope to obtain Raman images of these regions, which would link the optical observations of heterogeneous nanostructures to their chemical composition. These innovative results, which already demonstrate the potential of Raman scattering for in situ measurement of the deterioration degree of ancient stained glass, merits a long term research project.

\section{ACKNOWLEGMENTS}

The authors thank the LRMH Director, Mrs Isabelle Pallot-Frossard, director of LRMH for her help and support. Special thanks to Drs Léo Mazerolles and Mrs Marie-France Trichet (CECM, CNRS, Vitry) for some EDS measurements and the C2RMF (Musée du Louvre, Paris) for the use of its MEB facilities. Mr François Romain and Gérard Sagon are acknowledged for their technical help and Mrs Linda Prinsloo (University of Pretoria) for her critical reading of the manuscript. 


\section{REFERENCES}

1. Clark D.E., Pantano C.G. Jr, Hench L.L., Corrosion of Glass, Books for Industry and the Glas Industry, New York, 1979.

2. Newton R.G., The Deterioration and Conservation of Painted Glass, a critical Bibliography. Corpus Vitrearum Medii Aevi Great Britain Occasional Paper II, British Academy, Oxford University Press, Oxford, 1982.

3. Perez y Jorba M;, Dallas J.P., News Letters du Comité Technique du Corpus Vitrearum, 1984; 37-38: 8.

4. Perez y Jorba M, Dallas J.P., Collongues R., Bahezre C., Martin J.C., Rivista della Stazione Experimentale del Vitro, 1984; 5: 121.

5. Gillies K.J.S., Cox G.A., Glastechnische Berichte, 1988; 61:75.

6. Cox G.A.,Ford B.A., J. Mater. Sci., 1989; 24: 3146.

7. Newton R., Davison S. Conservation of glass, Butterworth, London, 1989.

8. Perez y Jorba M, Mazerolles L., Michel D., Rommeluèere M., Bahezre C., Compterendu du $1^{\text {er }}$ Colloque du Programme Franco-Allemand de recherche pour la Conservation des Monuments Historiques, 1993 ; pp213-219.

9. Cox G.A.,Ford B.A., J. Mater. Sci., 1993; $28: 5637$.

10. Bunker B.C., J. Non-Crystall. Solids, 1994; 179: 300.

11. Bunker B.C., Arnold G.W., Beauchamp E.K., J. Non-Cryst. Solids 1983; 58: 295.

12. Pollard A.M., Heron C., Archaeological Chemistry, RSC Paperbacks, Cambridge,1996, ch. 5, pp149-195.

13. Verità M. Glass, its nature, properties and deterioration mechanisms, in Sciences and technologies of the materials and of the environment for the protection of stained-glass and stone monuments, Créteil, 1998, pp29-39.

14. Libourel G., Sterpenich J., Barbey P., Chaussidon M., Caracterisation microstructurale, minéralogique et chimique de l'altération des vitraux, in Le matériau vitreux : verre et vitraux, Lefèvre R.-A., Pallot-Frossard I. Eds, Centro Universatario Europeo per i Beni Culturali, Ravello, Edipuglia, 1998, pp75-89.

15. Römich H., Laboratory experiments to stimulate corrosion on stained glass window, in The Conservation of Glass and Ceramics, Tennent N.H. Ed., James, London, 1999, pp 57-65.

16. Robinet L., Eremin K., Fearn S.,Pulham C., Hall C., Mater. Res. Soc. Symp. Proc. 2005; 852E: OO8.8.1.

17. Colomban Ph, Glasses, Glazes and Ceramics - Recognition of the Ancient Technology from the Raman Spectra, chapter in Raman Spectroscopy in Archaeology and Art History, Edwards H.G.M. and Chalmers J.M. (Eds), Royal Society of Chemistry, London, 2005, ch. 13, pp 192-206.

18. Colomban Ph., Mater. Res. Soc. Symp. Proc. 2005; 852E: OO8.3.1.

19. Mysen BO, Virgo D, Scarfe C. Am. Mineral. 1980; 65: 690.

20. Seifert F, Mysen BO, Virgo D. Am. Mineral. 1982; 67: 696.

21. Colomban Ph. J. Non-Crystalline Solids, 2003; 322: 180.

22. Colomban Ph., Paulsen O., J. Amer. Ceram. Soc. 2005; 88: 390.

23. Geotti-Bianchini F., Nicola C., Preo M., Vallotto M., Verità M., Rivista della Stazione Sperimentale del Vetro, 2005; 35-3:49.

24. Etcheverry M.P., Trocellier P., Djanarthany S., Beck L., Magassouba B., Rivista della Stazione Sperimentale del Vetro, 2005; 35-3: 63.

25. Colomban Ph., The corrosion of ceramic matrix composites, Materials Science Forum 1997; 251/254, Part 2: 835. 
26. Scanu T., Gugliemi J., Colomban Ph., Solid State Ionics, 1994; 70-71: 109.

27. Scanu T., Colomban Ph., J. Physique IV, 1993 ; C7 : 1927.

28. Colomban Ph., Lucazeau G., Mercier R., Novak A., J. Chem. Phys. 1977; 67: 5244.

29. Colomban Ph., Tournié A., Bellot-Gurlet L., J. Raman Spectrosc., submitted.

30. Colomban Ph. Schreiber H., J. Raman Spectrosc. 2005; 36: 884.

31. Colomban Ph, March G, Mazerolles L, Karmous T, Ayed N, Ennabli A, Slim H. J. Raman Spectrosc., 2003; 34: 205.

32. Colomban Ph., Ed., Proton Conductors, Cambridge University Press, Cambridge, 1992.

33. Colomban Ph., J. Molecular Struct., 1992; 270 : 407.

34. Greaves G.N., Fontaine A., Lagarde P., Raoux D., Gurman S.J., Nature, 1981; 293: 611.

35. Carabatos-Nédelec C., Raman Scattering of Glass, ch 10 in Handbook of Raman Spectroscopy, Lewis I.R. \& Edwards H.G.M. Eds, Marcel Dekker, Inc., New York, 2001. 


\section{Figure Captions}

Plate 1 : Examples of glass pieces studied. Note the corrosion dots of some glasses. Samples have been scanned on their flat surface and cut sections, as well on white and black paper in order to highlight the grisaille and the corrosion dots.

Fig. 1 : Representative Raman spectra selected among those of the samples listed in Table 1. Spectra have been recorded at the sample surface (analyzed depth $>50 \mu \mathrm{m}$ or more).

Fig. 2 Representative Raman signatures of the three types of stained glass. Baselines have been subtracted following the 4-segment procedure, which eliminates the Boson peak. The signature of red metal particle containing sample (red flashed glass) is also shown. Wavenumber and peak area components are given in Table 2.

Fig. 3 : Comparison of EDS spectra recorded on pristine glass core (top) and surface film section (bottom) after 20h treatment in sulfuric acid. Samples have been broken just before the examination.

Fig. 4 : Sample sections after $20 \mathrm{~h}$ thermal treatment in sulfuric acid for the different type of glass.

Fig. 5 : Corrosion film thickness as a function of sample type plotted versus time and square root of time.

Fig. 6 : Representative microstructures of 20 h treated Type 1 (a) and Type 3 (b) sample section; c) $20 \mathrm{~h}$ treated type 3 surface; d) 5 minute treated Type 3 sample section.

Fig. 7 : Representative IR spectra showing the transformation of the pristine glass in the ionexchanged silicate network for Type $3(\mathrm{~K}-\mathrm{Ca})$ and Type $2(\mathrm{Na}-\mathrm{Ca})$ glass ; *, impurities of the CsI matrix.

Fig. 8: Representative Raman spectra showing the transformation of the pristine glass in the ion-exchanged silicate network; bottom macro spectra: pristine glass, no base line was subtracted; other spectra recorded at the sample surface after (10 and) $20 \mathrm{~h}$ treatment in sulfuric acid, using macro-setting (analysed depth $>100 \mu \mathrm{m}$ ) ; top spectra have been recorded under microscope to highlight the structure of the outer surface layer (analysed surface from $\sim 10 \mu \mathrm{m}$ for Type 3 sample to $\sim 2 \mu \mathrm{m}$ for Type 1 sample).

Fig. 9 : Sketch of the silicate network according the Modified Random Network, after ref. [34], showing the alkali ion heterogeneity.

Fig. 10 : Plot of the relationship between the peak area of the ca. $590 \mathrm{~cm}^{-1}$ band (normalized versus the $\delta \mathrm{Si}-\mathrm{O}$ massif) and the $950 \mathrm{~cm}^{-1}$ band (normalized vs. the $v$ Si-O massif). 
Table 1: Samples studied in this work. Samples in italics have been selected for ion exchange treatment.

Table 2: Raman component wavenumber $\left(\mathrm{Q}_{\mathrm{n}}\right)$ and polymerization index (Ip) of representative samples (types 1, 2 and 3 glasses). Spectra have been recorded at the sample surface (analyzed depth $>50 \mu \mathrm{m}$ ).

Table 3: Examples of representative compositions of type 1, 2 \& 3 glasses.

Table 4 : Assignment of IR bands of representative samples (types 2 and 3 glasses) before and after acid sulfuric treatment. 
Table 1: Samples studied in this work. Samples in italics have been selected for ion exchange treatment.

\begin{tabular}{|c|c|c|c|c|}
\hline Origin & Date & Colour & Label & Type \\
\hline Amiens cathedral & $19^{\text {th }} \mathrm{c}$. & green & AM19vert & 1 \\
\hline Amiens cathedral & $19^{\text {th }} \mathrm{c}$ & greenish & AM19verdâtre & 1 \\
\hline Amiens cathedral & $19^{\text {th }} \mathrm{c}$. & purple & AM19pourpre & 1 \\
\hline Aube church & $15^{\text {th }}-16^{\text {th }} \mathrm{c}$. & Pale purple & AU15 & 1 \\
\hline Amiens cathedral & $19^{t h} \mathrm{c}$ & Amber-yellow & AM19jaune & 2 \\
\hline Amiens cathedral & $13^{\text {th }}$ c. $(?)$ & Yellow + "grisaille" (glass peint) & AM0 & 3 \\
\hline Amiens cathedral & $13^{\text {th }} \mathrm{c}$. & Pale green & AM1 & 3 \\
\hline Amiens cathedral & $13^{\text {th }} \mathrm{c}$. & blue & AM3 & 3 \\
\hline Amiens cathedral & $13^{\text {th }} \mathrm{c}$. & blue + "grisaille" (glass peint) & AM5 & 3 \\
\hline Amiens cathedral & $13^{\text {th }} \mathrm{c}$. & blue & AM14 & 3 \\
\hline Aube church & $15^{\text {th }}-16^{\text {th }} \mathrm{c}$. & $\begin{array}{l}\text { colourless glass with a red flashed } \\
\text { layer }\end{array}$ & AU9 & 3 \\
\hline Amiens cathedral & $13^{\text {th }}-14^{\text {th }} \mathrm{c}$ & $\begin{array}{l}\text { colourless glass with a red flashed } \\
\text { layer }\end{array}$ & AM13 & 3 \\
\hline Amiens cathedral & $13^{\text {th }}-14^{\text {th }} \mathrm{c}$. & $\begin{array}{l}\text { colourless glass with a red flashed } \\
\text { layer }\end{array}$ & AM22 & 3 \\
\hline Amiens cathedral & $19^{\text {th }} \mathrm{c}$ & dark blue & AM19bleu & 3 \\
\hline Le Mans & $13^{\text {th }}-15^{\text {th }} \mathrm{c}$. & pale blue & LM3 & 3 \\
\hline Le Mans & $13^{\text {th }} \mathrm{c}$. & blue & LM8 & 3 \\
\hline Köln & $21^{\text {th }} \mathrm{c}$. & pale brown (Vidrio 7d) & $\mathrm{C} 1$ & 3 \\
\hline Köln & $21^{\text {th }} \mathrm{c}$. & green (Vidrio 12d) & $\mathrm{C} 2$ & 3 \\
\hline Sainte-Chapelle & $21^{\text {th }} \mathrm{c}$. & blue (Vidrio) & SC21bleu & 3 \\
\hline Sainte-Chapelle & $21^{\text {th }} \mathrm{c}$. & violet (Vidrio) & SC21mauve & 3 \\
\hline Troyes Basilica & $21^{\text {th }} \mathrm{c}$. & pale yellow (Vidrio) & TR21jaune & 3 \\
\hline Aube church & $15^{\text {th }}-16^{\text {th }} \mathrm{c}$. & pale green & AU8 & 3bis \\
\hline Aube church & $15^{\text {th }}-16^{\text {th }} \mathrm{c}$. & blue & AU16bleu & 3bis \\
\hline Beauvais cathedral & $17^{\text {th }} \mathrm{c}$ & blue & B1 & 3bis \\
\hline Aube & $15^{\text {th }}-16^{\text {th }} \mathrm{c}$. & Lavender blue & AU2 & 3bis \\
\hline Strasbourg & $14^{\text {th }}-15^{\text {th }} \mathrm{c}$. & Colourless glass with yellow layer & $\mathrm{S} 1$ & 3bis \\
\hline Rouen & $15^{\text {th }} \mathrm{c}$. & Yellow-brown & $\mathrm{R} 1$ & 3bis \\
\hline
\end{tabular}


Table 2: Raman component wavenumber $\left(\mathrm{Q}_{\mathrm{n}}\right)$ and polymerization index (Ip) of representative samples (types 1, 2 and 3 glasses). Spectra have been recorded at the sample surface (analyzed depth $>50 \mu \mathrm{m}$ ).

\begin{tabular}{|c|c|c|c|c|c|c|}
\hline Items & $I_{P}$ & $\mathbf{Q}_{0}$ & $\mathbf{Q}_{1}$ & $\mathbf{Q}_{\mathbf{2}}$ & $\mathbf{Q}_{3}$ & $\mathbf{Q}_{4}$ \\
\hline \multicolumn{7}{|l|}{ type1 } \\
\hline AM19vert & 0.99 & 792 & 948 & 1047 & 1100 & 1149 \\
\hline AM19pourpre & 0.72 & 792 & 940 & 1002 & 1096 & 1185 \\
\hline AM19verdatre & 0.75 & 800 & 940 & 1002 & 1090 & 1164 \\
\hline $\mathrm{AU} 15$ & 1.2 & 786 & 875 & 995 & 1080 & 1154 \\
\hline mean value & 0.92 & 792.50 & 925.75 & 1011.50 & 1091.50 & 1163.00 \\
\hline$\Delta$ & 0.23 & 5.74 & 34.04 & 23.90 & 8.70 & 15.94 \\
\hline \multicolumn{7}{|l|}{ type2 } \\
\hline AMvjaune1 & 0.94 & 769 & 950 & 1053 & 1104 & 1150 \\
\hline \multicolumn{7}{|l|}{ type3 } \\
\hline AM0 & 1.5 & 782 & 906 & 997 & 1086 & 1186 \\
\hline AM1 & 0.9 & 780 & 875 & 988 & 1080 & 1159 \\
\hline AM3 & 0.8 & 782 & 858 & 1011 & 1083 & 1151 \\
\hline AM5 & 1 & 779 & 873 & 1014 & 1081 & 1133 \\
\hline AM14 & 0.8 & 787 & 868 & 1008 & 1080 & 1158 \\
\hline AU9 & 1 & 778 & 847 & 988 & 1082 & 1190 \\
\hline AM13 & 0.8 & 793 & 869 & 983 & 1060 & 1169 \\
\hline AM22 & 1.3 & 779 & 875 & 1004 & 1073 & 1116 \\
\hline AM19bleu & 0.73 & 774 & 926 & 1003 & 1093 & 1178 \\
\hline LM3 & 0.6 & 776 & 874 & 1007 & 1077 & 1139 \\
\hline LM8 & 0.7 & 773 & 875 & 995 & 1067 & 1114 \\
\hline $\mathrm{C} 1$ & 0.9 & 795 & 868 & 1013 & 1076 & 1160 \\
\hline $\mathrm{C} 2$ & 0.8 & 780 & 871 & 995 & 1060 & 1120 \\
\hline sc21bleu & 0.67 & 776 & 923 & 1001 & 1088 & 1246 \\
\hline SC21mauve & 0.66 & 787 & 870 & 967 & 1086 & 1241 \\
\hline TR21jaune & 0.77 & 776 & 884 & 1009 & 1084 & 1170 \\
\hline mean value & 0.87 & 781.06 & 878.88 & 998.94 & 1078.50 & 1164.38 \\
\hline$\Delta$ & 0.24 & 6.43 & 21.54 & 12.68 & 9.46 & 38.85 \\
\hline \multicolumn{7}{|l|}{ type3bis } \\
\hline AU8v1 & 1.2 & 784 & 880 & 991 & 1069 & 1144 \\
\hline AU16bleu & 0.96 & 776 & 884 & 1001 & 1080 & 1164 \\
\hline B1v1 & 0.9 & 788 & 871 & 1006 & 1077 & 1153 \\
\hline$A U 2 v 1$ & 1.4 & 788 & 866 & 999 & 1066 & 1136 \\
\hline $\mathrm{R} 1 \mathrm{v} 1$ & 1 & 784 & 860 & 1016 & 1091 & 1160 \\
\hline S1v1 & 1.2 & 781 & 849 & 1014 & 1088 & 1152 \\
\hline mean value & 1.11 & 783.50 & 868.33 & 1004.50 & 1078.50 & 1151.50 \\
\hline$\Delta$ & 0.19 & 4.55 & 12.94 & 9.48 & 9.97 & 10.27 \\
\hline
\end{tabular}


Table 3: Examples of representative compositions of type 1, 2 \& 3 glasses.

\begin{tabular}{|c|c|c|c|c|}
\hline \multirow[t]{2}{*}{ Oxyde / \% } & \multirow[t]{2}{*}{$\begin{array}{l}\text { Type } 1 \\
\text { (Ca silicate) }\end{array}$} & \multirow[t]{2}{*}{$\begin{array}{l}\text { Type } 2 \\
\text { (Na-Ca silicate) }\end{array}$} & \multicolumn{2}{|c|}{$\begin{array}{l}\text { Type } 3 \\
\text { (K-Ca silicate) }\end{array}$} \\
\hline & & & Ancient & Replica \\
\hline $\mathrm{SiO}_{2}$ & $60-70$ & 63 & 50 & 53 \\
\hline $\mathrm{Al}_{2} \mathrm{O}_{3}$ & $2-3$ & 2 & 2.5 & 2 \\
\hline $\mathrm{Na}_{2} \mathrm{O}$ & $8-14$ & 18 & $1-3$ & 1 \\
\hline $\mathrm{K}_{2} \mathrm{O}$ & $0.5-1.5$ & 1.5 & 18.5 & 18 \\
\hline $\mathrm{CaO}$ & $16-18$ & 15 & 14.5 & 16 \\
\hline $\mathrm{MgO}$ & 2.5 & 0.2 & $4-6$ & 5 \\
\hline $\mathrm{P}_{2} \mathrm{O}_{5}$ & 0.2 & $<0.05$ & $3.5-4$ & 4 \\
\hline $\mathrm{Fe}_{2} \mathrm{O}_{3}$ & 0.5 & 0.2 & 1 & 0.5 \\
\hline $\mathrm{MnO}$ & 0.3 & $<0.1$ & 1 & 1 \\
\hline $\mathrm{PbO}$ & 0.6 & 0 & 0 & 0 \\
\hline others & $<1$ & $<1$ & $<1$ & $<1$ \\
\hline $\mathrm{CaO} / \mathrm{Na}_{2} \mathrm{O}$ & $1-2$ & 0.8 & $>6$ & 16 \\
\hline $\mathrm{CaO} / \mathrm{K}_{2} \mathrm{O}$ & $>10$ & 10 & $\sim 0.8$ & $\sim 0.9$ \\
\hline
\end{tabular}


Table 4 : Assignment of IR bands of representative samples (types 2 and 3 glasses) before and after acid sulfuric treatment.

\begin{tabular}{|c|c|c|c|c|}
\hline Type 3 glass & & Type 2 glass & & Assignment \\
\hline pristine & $\mathrm{H}_{2} \mathrm{SO}_{4}$ treated & pristine & $\mathrm{H}_{2} \mathrm{SO}_{4}$ treated & \\
\hline $285 \mathrm{w}$ & $255 \mathrm{w}$ & $\begin{array}{l}255 \mathrm{vw} \\
410 \mathrm{sh}\end{array}$ & $260 \mathrm{vw}$ & $\mathrm{R}^{\prime} \mathrm{SiO}_{4}$ \\
\hline $460 \mathrm{~S}$ & $465 \mathrm{~S}$ & $468 \mathrm{~S}$ & $460 \mathrm{~S}$ & $\delta \mathrm{Si}-\mathrm{O}$ \\
\hline $500 \mathrm{sh}$ & & $510 \mathrm{sh}$ & & \\
\hline $\begin{array}{l}605 \mathrm{w} \\
670 \mathrm{vw}\end{array}$ & $600 \mathrm{w}$ & $610 \mathrm{sh}$ & $620 \mathrm{w}$ & \\
\hline $775 \mathrm{~m}$ & $800 \mathrm{~m}$ & $770 \mathrm{~m}$ & $795 \mathrm{~m}$ & $v \mathrm{Si}-\mathrm{O}-\mathrm{Si}$ \\
\hline $950 \mathrm{sh}$ & & $950 \mathrm{~S}$ & & \\
\hline $1030 \mathrm{vS}$ & $1100 \mathrm{vS}$ & $1050 \mathrm{vS}$ & $1080 \mathrm{vS}$ & $v \mathrm{Si}-\mathrm{O}$ \\
\hline $1180 \mathrm{sh}$ & $1220 \mathrm{sh}$ & & $1250 \mathrm{sh}$ & \\
\hline $1600 \mathrm{w}$ & & $1600 \mathrm{w}$ & & \\
\hline & $1635 \mathrm{w}$ & & $1660 \mathrm{w}$ & $\delta \mathrm{H}_{2} \mathrm{O}$ \\
\hline & $1720 \mathrm{w}$ & $1720 \mathrm{vw}$ & $1740 \mathrm{w}$ & $\delta \mathrm{H}_{3} \mathrm{O}^{+}$ \\
\hline
\end{tabular}

Pristine : powdered sample core

$\mathrm{H}_{2} \mathrm{SO}_{4}$ treated : powdered surface film. 


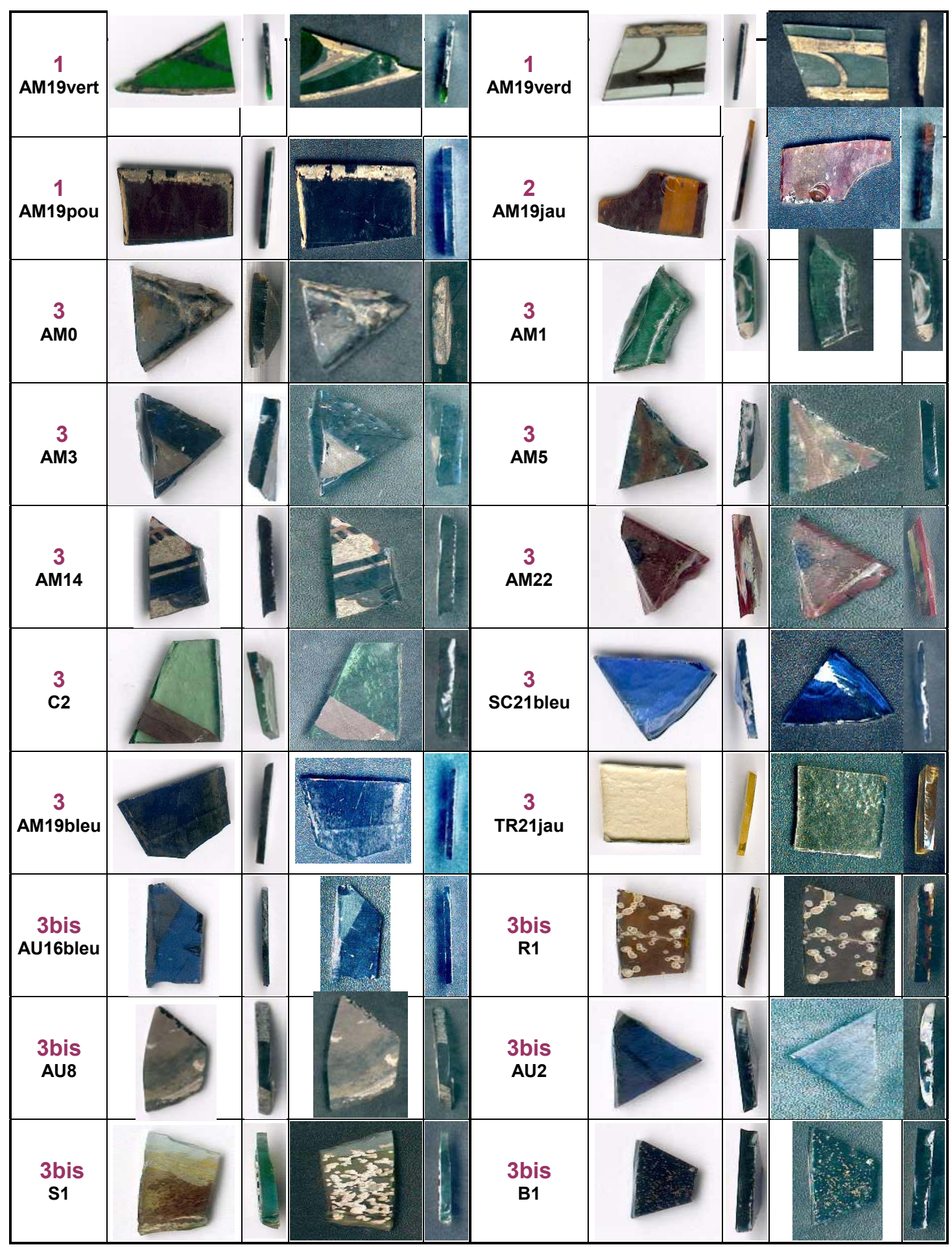

Plate 1 : Examples of glass pieces studied. Note the corrosion dots of some glasses. Samples have been scanned on their flat surface and cut sections, as well on white and black paper in order to highlight the grisaille and the corrosion dots. 

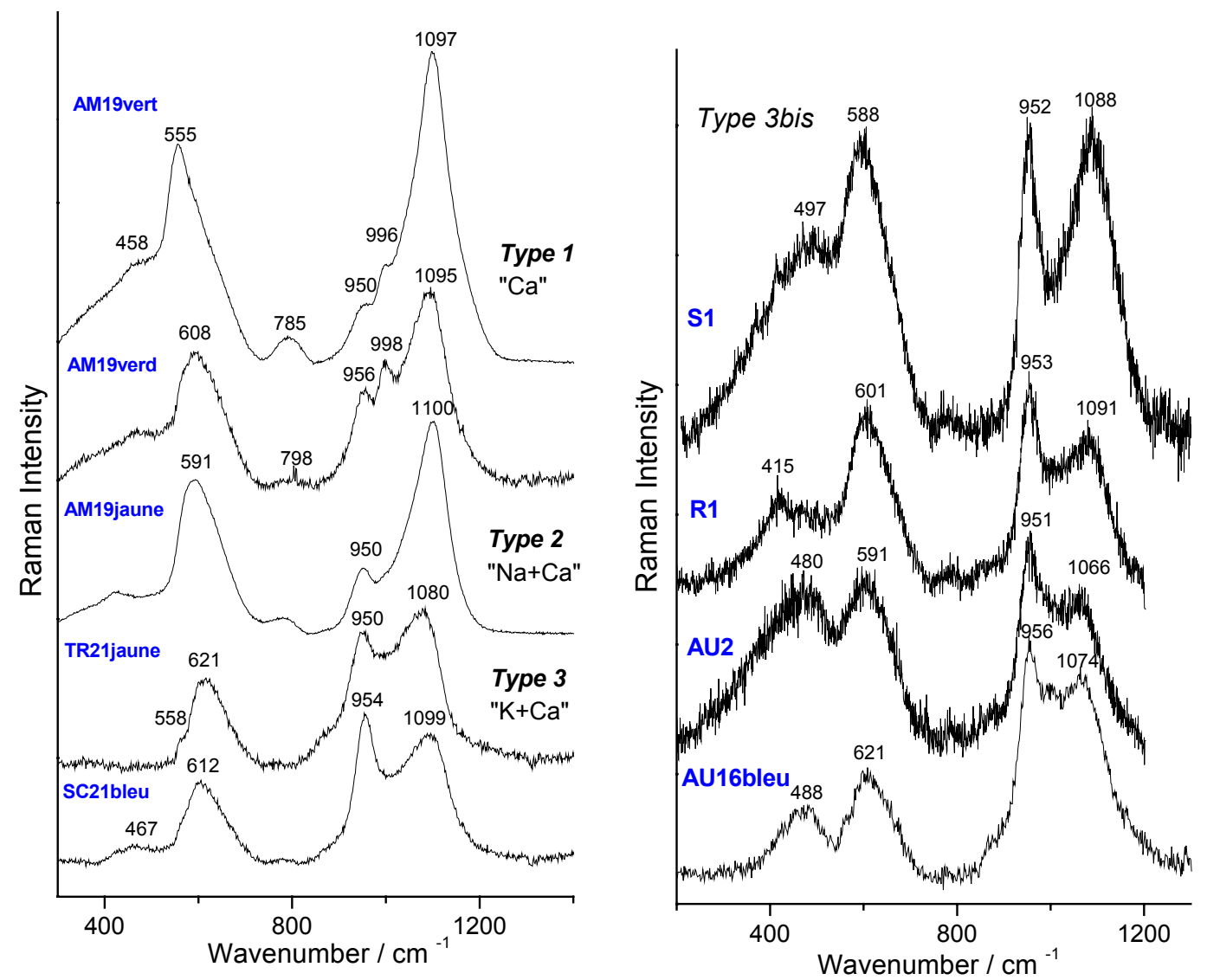

Fig. 1 : Representative Raman spectra selected among those of the samples listed in Table 1. Spectra have been recorded at the sample surface (analyzed depth $>50 \mu \mathrm{m}$ or more). 


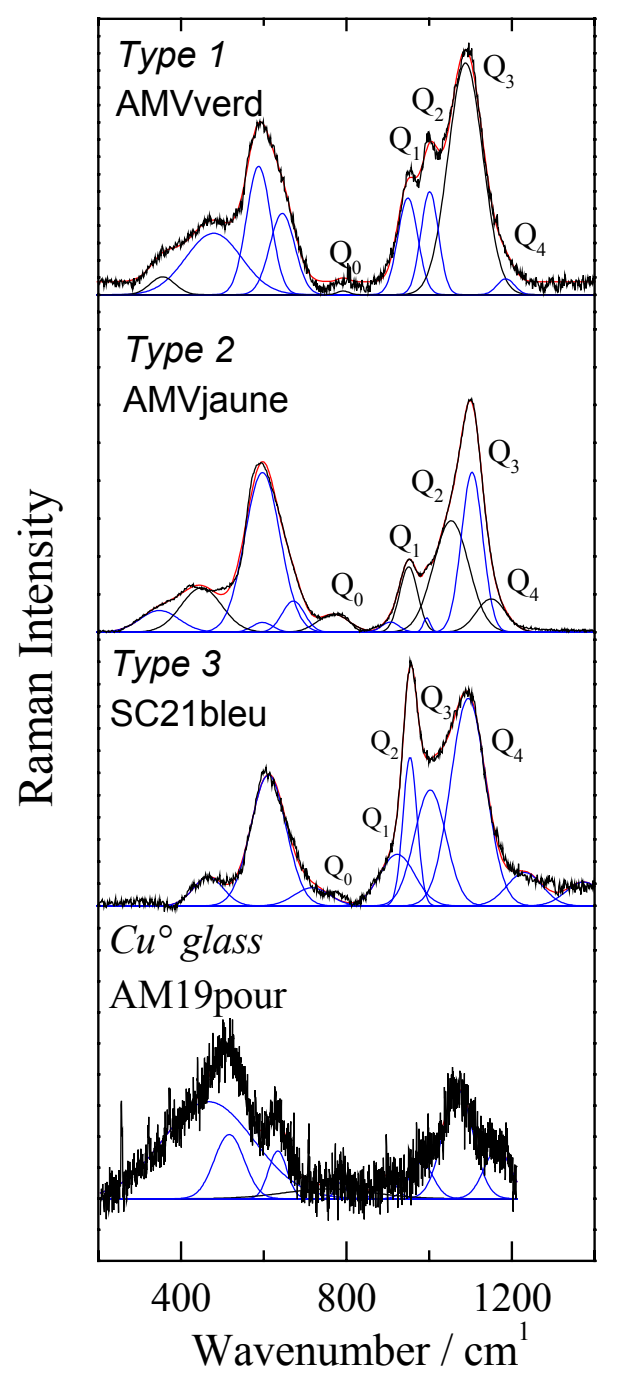

Fig. 2 Representative Raman signatures of the three types of stained glass. Baselines have been subtracted following the 4-segment procedure, which eliminates the Boson peak. The signature of red metal particle containing sample (red flashed glass) is also shown. Wavenumber and peak area components are given in Table 2. 


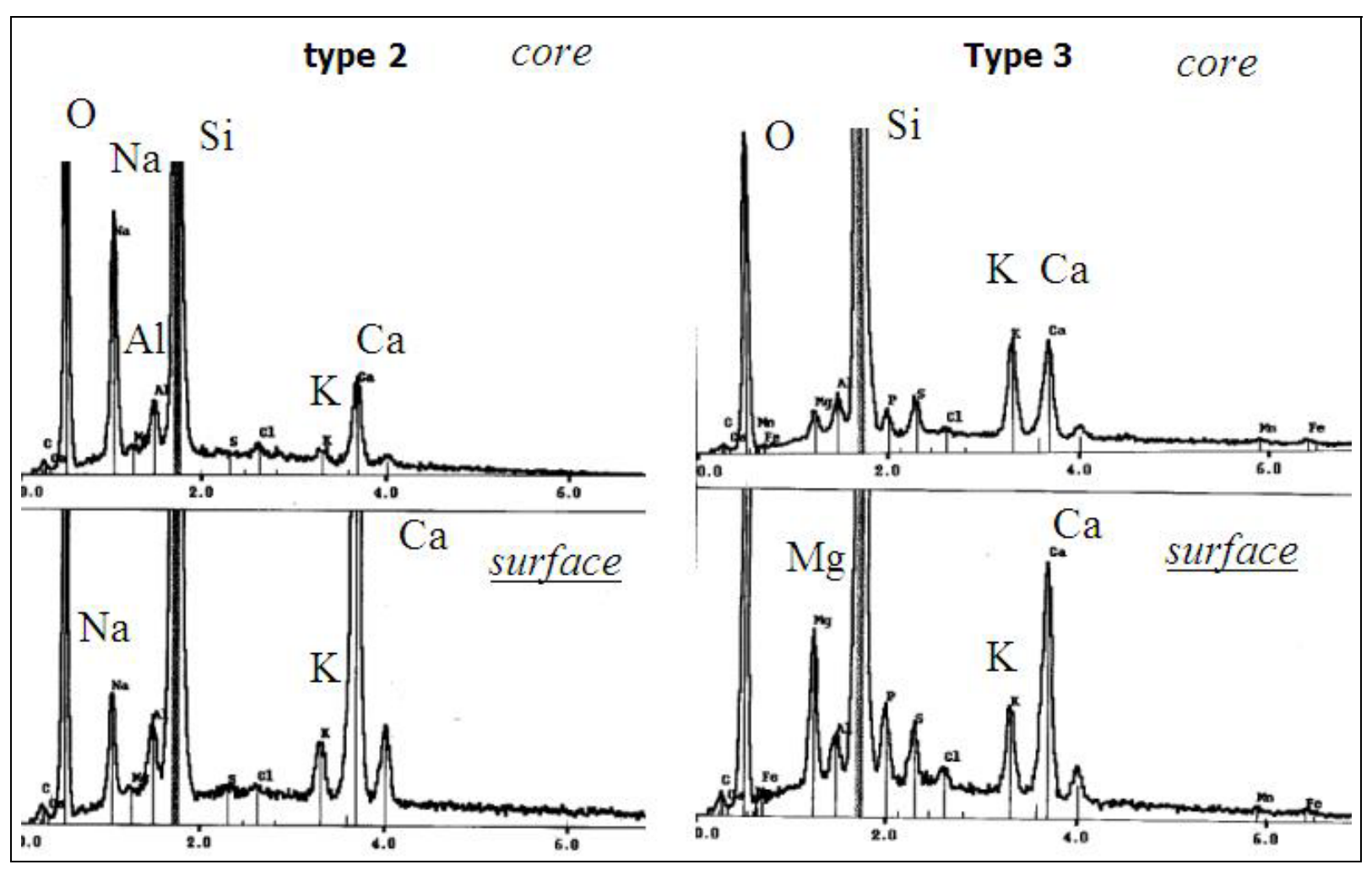

Fig. 3 : Comparison of EDS spectra recorded on pristine glass core (top) and surface film section (bottom) after 20h treatment in sulfuric acid. Samples have been broken just before the examination. 
Type 1

Type 2

Type 3

Fig. 4 : Sample sections after $20 \mathrm{~h}$ thermal treatment in sulfuric acid for the different type of glass.

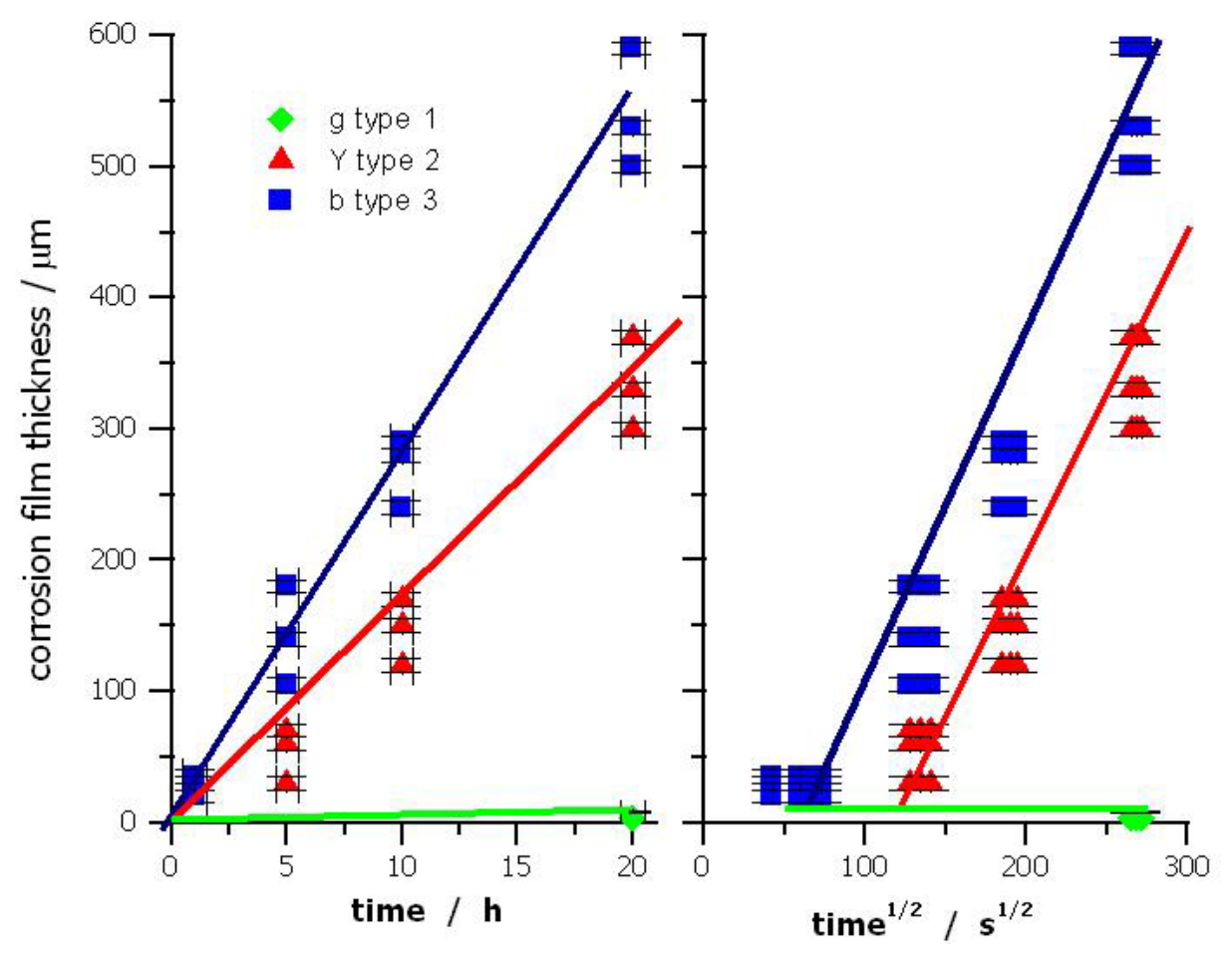

Fig. 5 : Corrosion film thickness as a function of sample type plotted versus time and square root of time. 


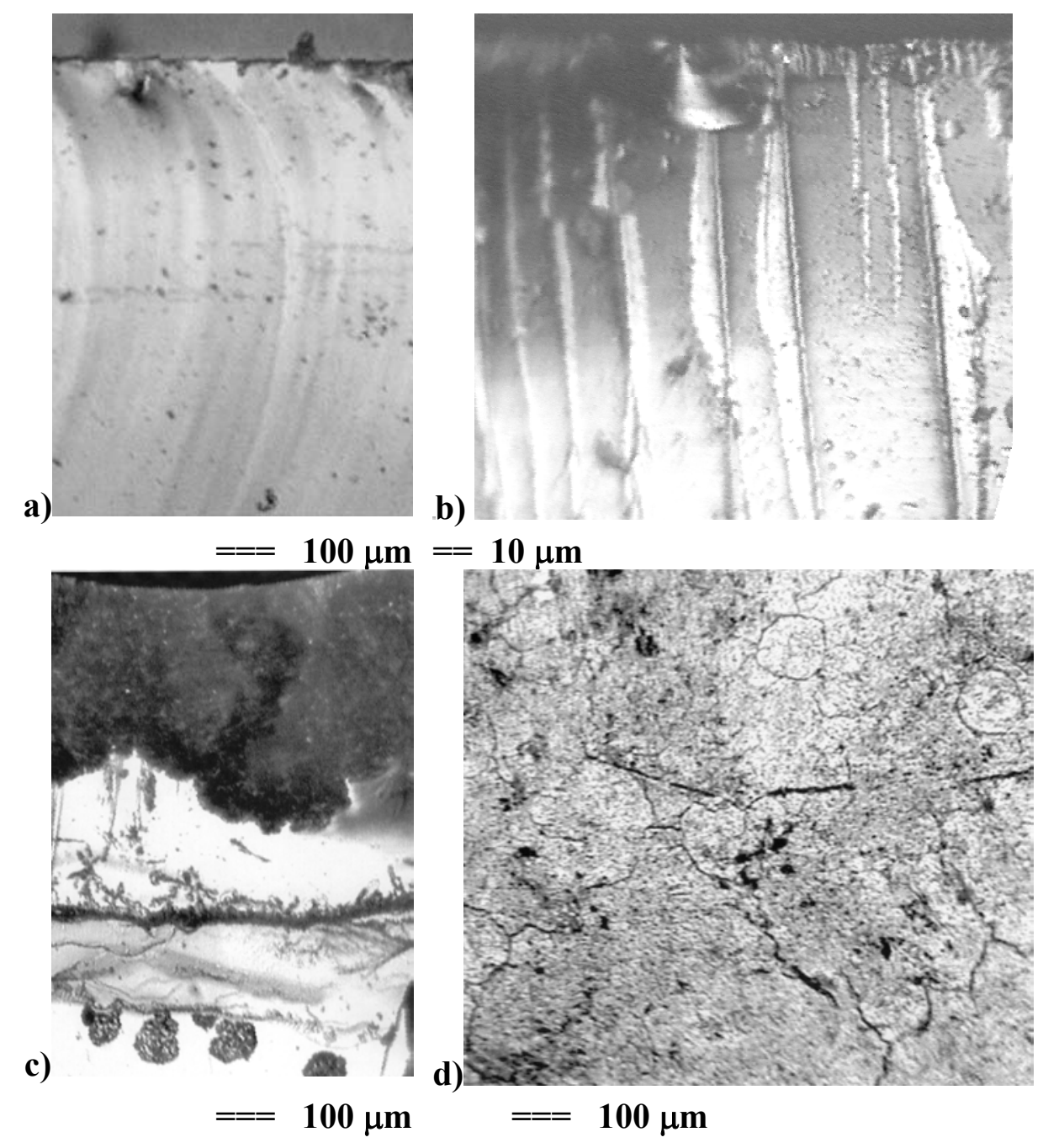

Fig. 6 : Representative microstructures of $20 \mathrm{~h}$ treated Type 1 (a) and Type 3 (b) sample section; c) $20 \mathrm{~h}$ treated type 3 surface; d) 5 minute treated Type 3 sample section. 


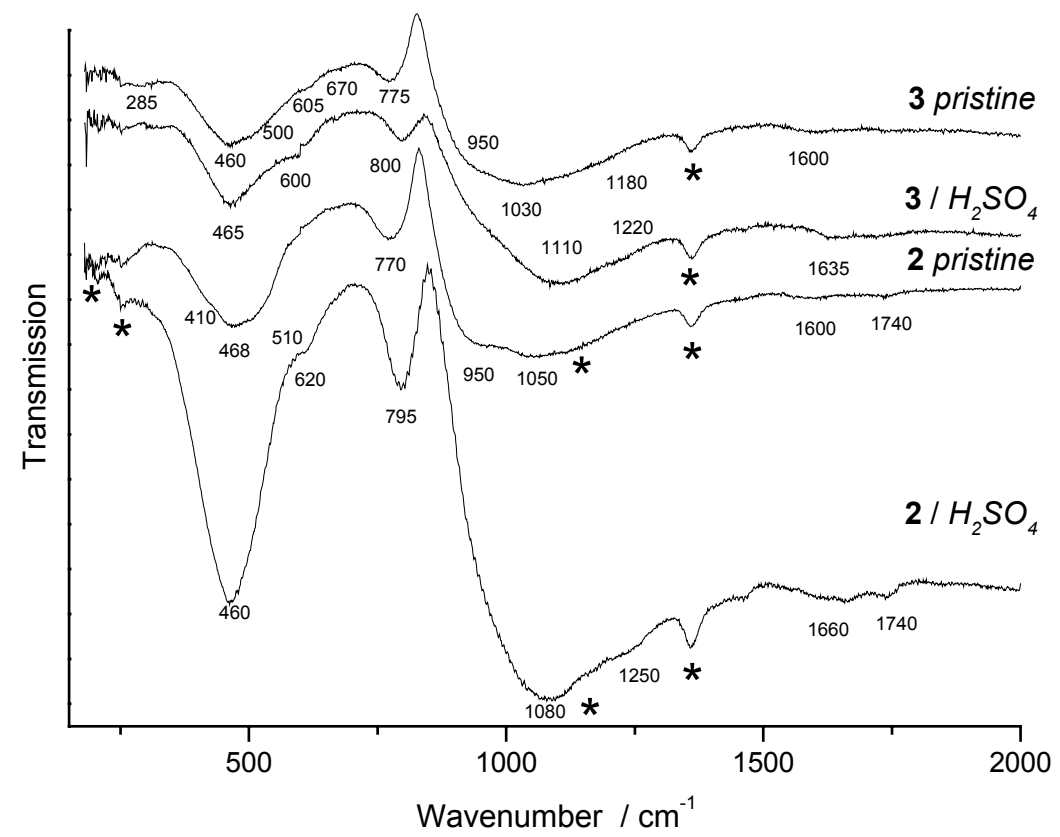

Fig. 7 : Representative IR spectra showing the transformation of the pristine glass in the ionexchanged silicate network for Type $3(\mathrm{~K}-\mathrm{Ca})$ and Type $2(\mathrm{Na}-\mathrm{Ca})$ glass ; *, impurities of the CsI matrix.
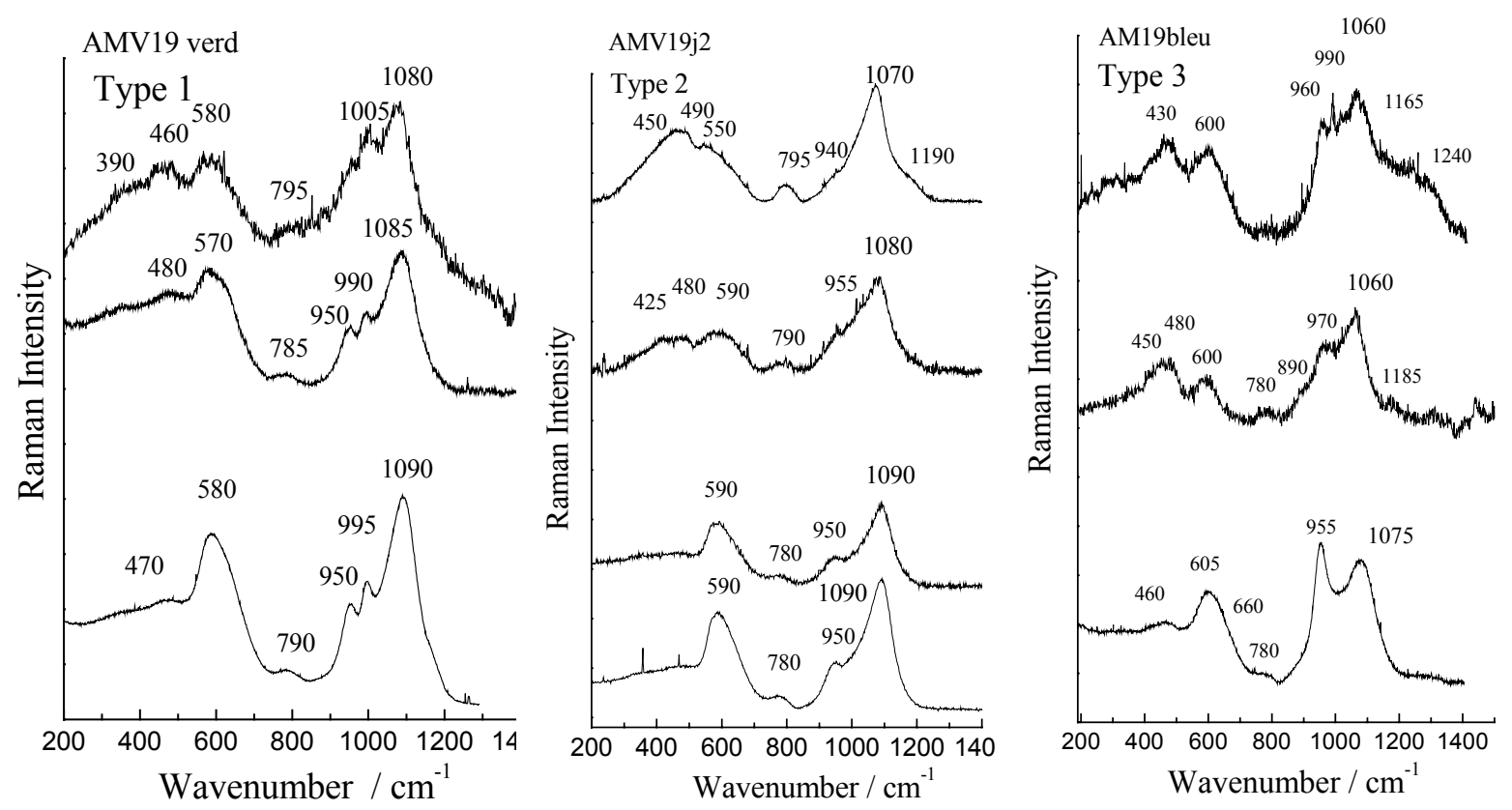

Fig. 8: Representative Raman spectra showing the transformation of the pristine glass in the ion-exchanged silicate network; bottom macro spectra: pristine glass, no base line was subtracted; other spectra recorded at the sample surface after (10 and) $20 \mathrm{~h}$ treatment in sulfuric acid, using macro-setting (analysed depth $>100 \mu \mathrm{m}$ ) ; top spectra have been recorded under microscope to highlight the structure of the outer surface layer (analysed surface from $\sim 10 \mu \mathrm{m}$ for Type 3 sample to $\sim 2 \mu \mathrm{m}$ for Type 1 sample). 


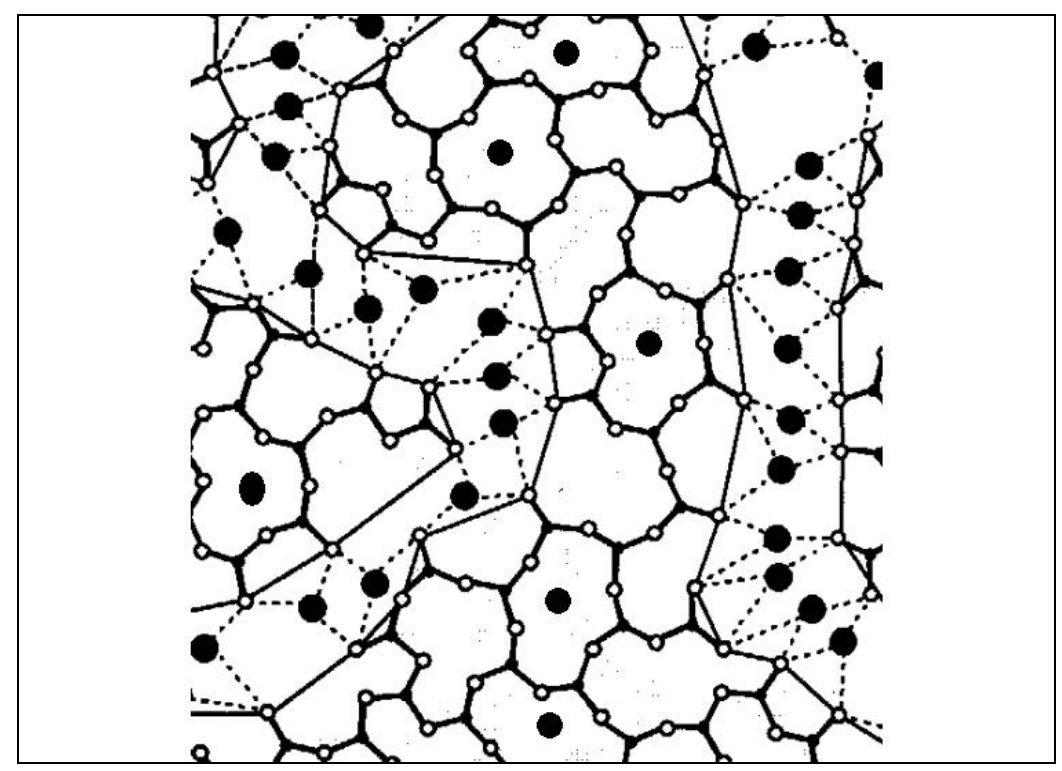

Fig. 9 : Sketch of the silicate network according the Modified Random Network, after ref. [34], showing the alkali ion heterogeneity.

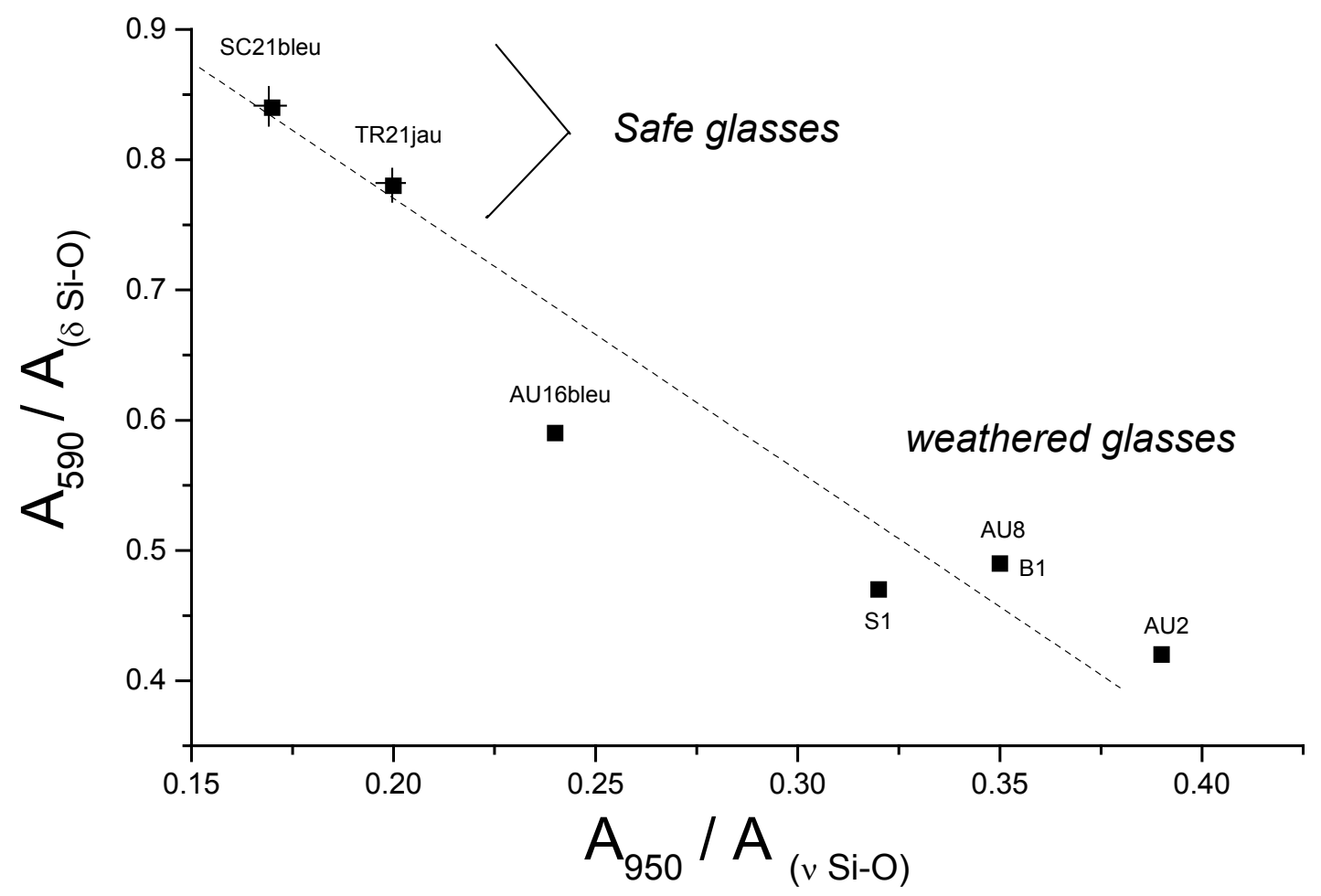

Fig. 10 : Plot of the relationship between the peak area of the ca. $590 \mathrm{~cm}^{-1}$ band (normalized versus the $\delta \mathrm{Si}-\mathrm{O}$ massif) and the $950 \mathrm{~cm}^{-1}$ band (normalized vs. the $v$ Si-O massif). 